Historic, Archive Document

Do not assume content reflects current scientific knowledge, policies, or practices. 
$+1$ 


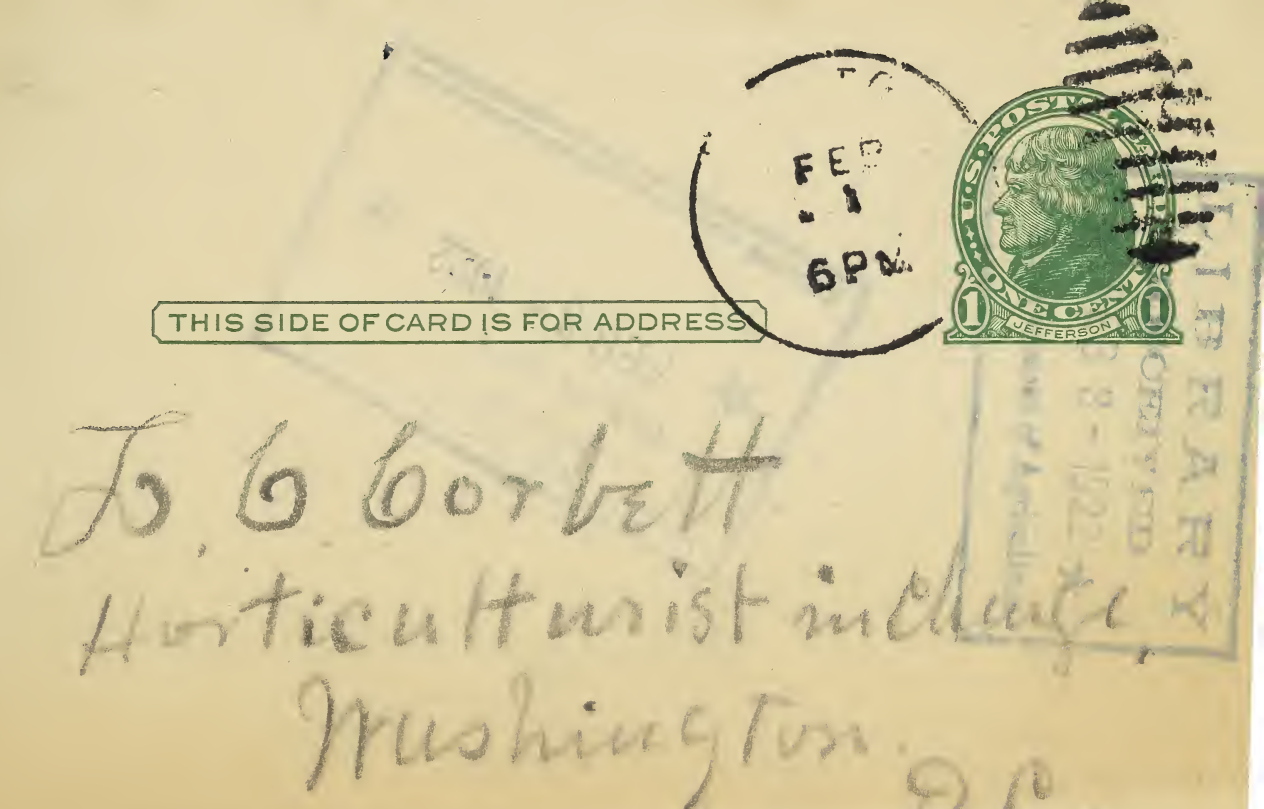




\section{PRICE LIST 1922}

Assortment choice kinds Peonies - Lavender, White, Red and Pink, two each, post paid ....... \$2.50 Clumps, 3 yrs, $\$ 1.75$; expressed; Clumps, 5 yrs, blooming size, $\$ 2.50$. 25 Clumps, 3 years old, $\$ 30 ; \quad 50$ 3 yrs old, $\$ 50 ; 25$ of 5 yr old Clumps, $\$ 40 ; 50$ of th e 5 yr old Clumps, $\$ 60$.

IRRIS-Named kinds; $\$ 3.50$ per 100: 2 each 8 kinds post paid, $\$ 1.35$; 4 each 8 kinds, p p., $\$ 2.25$--all color $s$ LILLY VALLEY PIPS-25 post paid.... \$1 20 MINT PLANTS - for garnishing lamb, 25 for 75c HOREHOUND Plants, .....25 for..... 75c ASPARAGUS " two yrs o!d, 100 fer $\$ 135$ HORSERADISH -50 for $\ldots \ldots \ldots \ldots \$ 1.00$ STRAWBERRY Plants- 100 Senator Durlop, post paid, $\$ 1.25$. 500 for $\$ 5$ by parcel post.

GRAPE VINES-Concord

$15 \mathrm{c}$ MISCELLANEOUS-Rhubarb, large $3 \mathrm{yr}$ old, 6 post paid, \$1.25. 12 Houton Gooseberries, p. p \$1.15, 25 California Privitt $12 x 18$ in, \$1 50.12 hardy Crysanthums, p. p, \$1.00. $2 \mathrm{~W}$ nite Lilacs, one foot, $75 \mathrm{c}$. 10 Tiger Lillys, \$1 00. 5 Bitter Sweet Plants, 2 to 3 feet, $\$ 125$. Red Cedar, 12 to 18 in 5 for $\$ 1.25$. Wild Grape Vines 50c each. Myrtle Plants, Blue Flowers. 10 for 75 c. Mixed kinds of Hollyhocks 20 for $\$ 1.00$. Oriental Poppys, 10 post pa 1, \$1 15 Dorothy Perkins Roses 50c each. 5 Blush Roses $\$ 1.00$. 10 Red Raspberries $\$ 1.00$. 10 Kansas Black Raspberries $\$ 1.15$

\section{ALVA Y. CATHCART,}

BRISTOL, INDIANA 